\title{
Development and validation of a patient-reported outcome measure for systemic sclerosis: the EULAR Systemic Sclerosis Impact of Disease (SclerolD) questionnaire
}

\author{
Mike O Becker 다, ${ }^{1}$ Rucsandra Dobrota 다, 'Alexandru Garaiman, ${ }^{1}$ \\ Rudolf Debelak 지 ${ }^{2,3}$ Kim Fligelstone, ${ }^{4}$ Ann Tyrrell Kennedy, ${ }^{5}$ Annelise Roennow, ${ }^{6}$ \\ Yannick Allanore, ${ }^{7}$ Patricia E Carreira, ${ }^{8}$ László Cziriák, ${ }^{9}$ Christopher P Denton (i) ${ }^{10}$ \\ Roger Hesselstrand ${ }_{1}^{11}$ Gunnel Sandqvist, ${ }_{11}^{11}$ Otylia Kowal-Bielecka, ${ }^{12}$

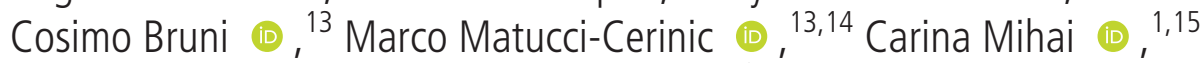 \\ Ana Maria Gheorghiu, ${ }_{15}^{15}$ Ulf Mueller-Ladner, ${ }^{16}$ Joseph Sexton, ${ }^{17}$ Tore K Kvien, ${ }^{17}$ \\ Turid Heiberg, ${ }^{18}$ Oliver Distler (1) ${ }^{1}$
}

\begin{abstract}
Handling editor Josef S Smolen

- Additional supplemental material is published online only. To view, please visit the journal online (http://dx.doi. org/10.1136/annrheumdis 2021-220702)
\end{abstract}

For numbered affiliations see end of article.

\section{Correspondence to}

Dr Oliver Distler, Department of Rheumatology, University of

Zurich, University Hospital

Zurich, 8091 Zurich,

Switzerland;

oliver.distler@usz.ch

MOB and RD contributed equally.

TH and OD contributed equally.

For 'Presented at statement' see end of article.

Received 5 May 2021

Accepted 9 November 2021

Check for updates

(C) Author(s) (or their employer(s)) 2021. No commercial re-use. See rights and permissions. Published by BMJ.

To cite: Becker $\mathrm{MO}$,

Dobrota R, Garaiman A, et al. Ann Rheum Dis Epub ahead of print: [please include Day Month Year]. doi:10.1136/

annrheumdis-2021-220702

\section{ABSTRACT}

Objectives Patient-reported outcome measures

(PROMs) are important for clinical practice and research. Given the high unmet need, our aim was to develop a comprehensive PROM for systemic sclerosis (SSc), jointly with patient experts.

Methods This European Alliance of Associations for Rheumatology (EULAR)-endorsed project involved 11 European SSc centres. Relevant health dimensions were chosen and prioritised by patients. The resulting Systemic Sclerosis Impact of Disease (ScleroID) questionnaire was subsequently weighted and validated by Outcome Measures in Rheumatology criteria in an observational cohort study, cross-sectionally and longitudinally. As comparators, SSc-Health Assessment Questionnaire (HAQ), EuroQol Five Dimensional (EQ-5D), Short Form-36 (SF-36) were included.

Results Initially, 17 health dimensions were selected and prioritised. The top 10 health dimensions were selected for the SclerolD questionnaire. Importantly, Raynaud's phenomenon, impaired hand function, pain and fatigue had the highest patient-reported disease impact. The validation cohort study included 472 patients with a baseline visit, from which 109 had a test-retest reliability visit and 113 had a follow-up visit (85\% female, 38\% diffuse SSc, mean age 58 years, mean disease duration 9 years). The total SclerolD score showed strong Pearson correlation coefficients with comparators (SSc-HAQ, 0.73; Patient's global assessment, Visual Analogue Scale 0.77; HAQ-Disability Index, 0.62; SF-36 physical score, -0.62 ; each $p<0.001$ ). The internal consistency was strong: Cronbach's alpha was 0.87 , similar to SSC-HAQ (0.88) and higher than EQ-5D (0.77). The ScleroID had excellent reliability and good sensitivity to change, superior to all comparators (intraclass correlation coefficient 0.84; standardised response mean 0.57 ).

Conclusions We have developed and validated the EULAR SclerolD, which is a novel, brief, disease-specific, patient-derived, disease impact PROM, suitable for research and clinical use in SSC.

\section{Key messages}

What is already known about this subject?

- Patient-reported outcome measures (PROMs) are important to integrate the patient's view into routine care.

- They are an integral part of clinical trials and required for registration of novel treatments.

- A brief and specific validated PROM for overall systemic sclerosis (SSc) is lacking.

What does this study add?

- It develops and validates the Systemic Sclerosis Impact of Disease (SclerolD), a disease-specific PROM that captures patient experience and SSc complexity in an easy to apply format for clinical care and clinical trials.

How might this impact on clinical practice or future developments?

- SclerolD can be used to integrate patient experience to improve decision making in clinical practice.

- Further studies are needed to validate ScleroID as a potential PROM for future clinical trials in SSc.

\section{INTRODUCTION}

Systemic sclerosis (SSc) is characterised by a chronic and frequently progressive course and by a high patient-to-patient variability. ${ }^{1} \mathrm{SSc}$ has one of the highest morbidities and case-specific mortalities among the connective tissue diseases. ${ }^{2} 3$ Overall, general health (as measured by the Short Form-36 (SF-36) and EuroQol Five Dimensional (EQ-5D) questionnaires), as well as quality of life and functional abilities (as measured by the Health Assessment Questionnaire Disability Index, HAQ-DI) are significantly reduced in SSc. ${ }^{4-6}$

A disease-specific, patient-reported outcome measure (PROM) for use in clinical trials and in 


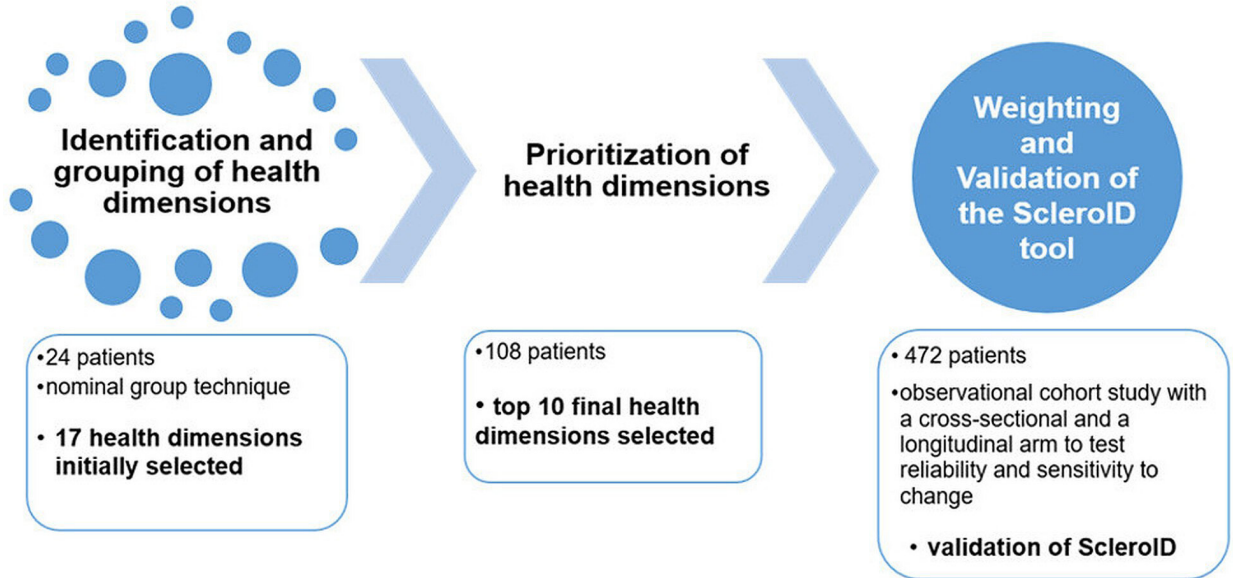

Figure 1 General SclerolD project workflow and procedure. ScleroID, Systemic Sclerosis Impact of Disease.

clinical practice in SSc that covers the different disease features of this multiorgan autoimmune disease is lacking. ${ }^{7}$ The European Medicines Agency recommends that sufficient evidence needs to be provided on the patient benefit by PROMs before granting approval of a new therapeutic agent, ${ }^{8}$ and PROMs need to be included as outcome measures in therapeutic randomised controlled trials (RCTs). Thus, the lack of sensitive, diseasespecific PROMs covering the overall disease is currently one of the greatest challenges for drug development in this devastating disease. In addition, published data show that systematic use of PROMs in clinical practice improves patient-physician communication and decision making, as well as patients' satisfaction. ${ }^{9}$

Research in the field of other autoimmune diseases provides the basis for the successful development of disease-specific PROMs. For rheumatoid arthritis, the Rheumatoid Arthritis Impact of Disease (RAID) questionnaire, ${ }^{10} 11$ and for psoriatic arthritis, the Psoriatic Arthritis Impact of Disease (PsAID) questionnaire, ${ }^{12}$ were designed to capture the burden of disease that is most important to patients. Furthermore, the RAID has been successfully used to identify thresholds for symptom states acceptable for patients, as well as evaluating onset of response to medication. ${ }^{13} 14$

In this study, we aimed to develop a novel, patient-derived PROM for SSc that is able to cover the global disease burdenthe EULAR Systemic Sclerosis Impact of Disease (ScleroID). Furthermore, we validated the ScleroID by the Outcome Measures in Rheumatology (OMERACT) filter in a large, multicentric, clinical cohort study. ${ }^{15}$

\section{METHODS}

The development of the European Alliance of Associations for Rheumatology (EULAR) ScleroID follows approaches used in the EULAR-endorsed RAID and PsAID questionnaires,

Table 1 Initially selected candidate health dimensions and their prioritisation ranking by importance

\begin{tabular}{|c|c|c|c|c|c|c|c|}
\hline No & Health dimensions* & Mean rank & Median rank & $\begin{array}{l}\text { Order by median } \\
\text { rank }\end{array}$ & $\begin{array}{l}\% \text { patients giving } \\
\text { rank } 1 \text { to the } \\
\text { dimension }\end{array}$ & $\begin{array}{l}\% \text { patients giving } \\
\text { rank } 1-3 \text { to the } \\
\text { dimension }\end{array}$ & $\begin{array}{l}\% \text { patients giving } \\
\text { rank } 1-10 \text { to the } \\
\text { dimension }\end{array}$ \\
\hline 1 & Raynaud & 5.8 & 5 & 1 & 19.4 & 36.1 & 84.3 \\
\hline 2 & Hand function & 6.7 & 5 & 1 & 8.3 & 25.0 & 78.7 \\
\hline 3 & Upper GI symptoms & 7.2 & 6 & 2 & 7.4 & 24.1 & 73.1 \\
\hline 4 & Pain & 6.9 & 6 & 2 & 10.2 & 25.9 & 75.9 \\
\hline 5 & Fatigue & 6.7 & 6 & 2 & 9.3 & 26.9 & 78.7 \\
\hline 6 & Lower Gl symptoms & 7.8 & 7 & 3 & 10.2 & 24.1 & 69.4 \\
\hline 7 & Limitation of life choices and activities & 8.3 & 8 & 4 & 4.6 & 20.4 & 66.7 \\
\hline 8 & Body mobility & 8.7 & 8,5 & 5 & 2.8 & 11.0 & 65.7 \\
\hline 9 & Breathlessness & 8.6 & 9 & 6 & 12.0 & 27.8 & 52.8 \\
\hline 10 & Digital ulcers & 9.5 & 10 & 7 & 1.9 & 17.6 & 54.6 \\
\hline 11 & Anxiety & 10.2 & 10 & 7 & 2.8 & 9.3 & 50.9 \\
\hline 12 & Dryness & 10.1 & 10 & 7 & 1.9 & 9.3 & 54.6 \\
\hline 13 & Appearance & 10.3 & 11 & 8 & 3.7 & 9.3 & 49.1 \\
\hline 14 & Concentration difficulties & 10.9 & 12 & 9 & 1.9 & 9.3 & 39.8 \\
\hline 15 & Cough & 11.3 & 13 & 10 & 1.9 & 10.2 & 38.9 \\
\hline 16 & Depression & 11.6 & 13 & 10 & 0.9 & 7.4 & 35.2 \\
\hline 17 & Calcinosis & 12.5 & 14 & 11 & 0.9 & 6.5 & 31.5 \\
\hline
\end{tabular}

*Patients from the prioritisation cohort were asked to rank the dimensions in order of their importance by giving a rank from 1 (most important) to 17 (least important). Each rank could only be used once. The top 10 dimensions with the lowest median rank (highest importance) were selected for the questionnaire. The 10-12th dimension had an equal median rank but the 10th dimension had a higher role for more patients (\% giving top rank, last two columns) and was consequently chosen in favour of dimensions 11 and 12. Dimensions included in the final SclerolD questionnaire are bolded.

GI, gastrointestinal; No, number; SclerolD, Systemic Sclerosis Impact of Disease. 
Table 2 The SclerolD questionnaire

\begin{tabular}{|c|c|c|c|c|c|c|c|c|c|c|c|c|}
\hline \multicolumn{13}{|c|}{ The EULAR SclerolD } \\
\hline \multicolumn{13}{|c|}{ How much have the different aspects of systemic sclerosis affected you during the last week? } \\
\hline \multicolumn{13}{|c|}{ Please mark your responses on the scale by choosing the appropriate no for each of the following dimensions: } \\
\hline \multicolumn{13}{|c|}{ Raynaud's phenomenon: } \\
\hline \multicolumn{13}{|c|}{ Circle the no that best describes the severity of your Raynaud's phenomenon during the last week: } \\
\hline None & 0 & 1 & 2 & 3 & 4 & 5 & 6 & 7 & 8 & 9 & 10 & Extreme \\
\hline \multicolumn{13}{|c|}{ Hand function: } \\
\hline \multicolumn{13}{|c|}{ Circle the no that best describes your hand function limitations due to your systemic sclerosis during the last week: } \\
\hline $\begin{array}{l}\text { No } \\
\text { limitation }\end{array}$ & 0 & 1 & 2 & 3 & 4 & 5 & 6 & 7 & 8 & 9 & 10 & $\begin{array}{l}\text { Extreme } \\
\text { limitation }\end{array}$ \\
\hline \multicolumn{13}{|c|}{ Upper gastrointestinal tract symptoms (eg, swallowing difficulties, reflux, vomiting): } \\
\hline \multicolumn{13}{|c|}{ Circle the no that best describes the severity of your upper gastrointestinal tract symptoms due to your systemic sclerosis during the last week: } \\
\hline None & 0 & 1 & 2 & 3 & 4 & 5 & 6 & 7 & 8 & 9 & 10 & Extreme \\
\hline \multicolumn{13}{|l|}{ Pain: } \\
\hline \multicolumn{13}{|c|}{ Circle the no that best describes the pain you felt due to your systemic sclerosis during the last week: } \\
\hline None & 0 & 1 & 2 & 3 & 4 & 5 & 6 & 7 & 8 & 9 & 10 & Extreme \\
\hline \multicolumn{13}{|l|}{ Fatigue: } \\
\hline \multicolumn{13}{|c|}{ Circle the no that best describes the impact of overall fatigue due to your systemic sclerosis during the last week: } \\
\hline None & 0 & 1 & 2 & 3 & 4 & 5 & 6 & 7 & 8 & 9 & 10 & Extreme \\
\hline \multicolumn{13}{|c|}{ Lower gastrointestinal tract symptoms (eg, bloating, diarrhoea, constipation, anal incontinence): } \\
\hline \multicolumn{13}{|c|}{ Circle the no that best describes the severity of lower gastrointestinal tract symptoms during the last week: } \\
\hline None & 0 & 1 & 2 & 3 & 4 & 5 & 6 & 7 & 8 & 9 & 10 & Extreme \\
\hline \multicolumn{13}{|c|}{ Limitations of life choices and activities (eg, social life, personal care, work): } \\
\hline \multicolumn{13}{|c|}{ Circle the no that best describes how severe the limitations of life choices and activities due to your systemic sclerosis were during the last week: } \\
\hline No & 0 & 1 & 2 & 3 & 4 & 5 & 6 & 7 & 8 & 9 & 10 & Extreme \\
\hline \multicolumn{13}{|c|}{ Body mobility: } \\
\hline \multicolumn{13}{|c|}{ Circle the no that best describes how much your body mobility was affected due to your systemic sclerosis during the last week: } \\
\hline Not affected & 0 & 1 & 2 & 3 & 4 & 5 & 6 & 7 & 8 & 9 & 10 & $\begin{array}{l}\text { Extremely } \\
\text { affected }\end{array}$ \\
\hline \multicolumn{13}{|c|}{ Breathlessness: } \\
\hline \multicolumn{13}{|c|}{ Circle the no that best describes how severe your breathlessness due to systemic sclerosis was during the last week: } \\
\hline None & 0 & 1 & 2 & 3 & 4 & 5 & 6 & 7 & 8 & 9 & 10 & Extreme \\
\hline \multicolumn{13}{|c|}{ Digital ulcers: } \\
\hline \multicolumn{13}{|c|}{ Circle the no that best describes how much your digital ulcers affected you overall during the last week: } \\
\hline None & 0 & 1 & 2 & 3 & 4 & 5 & 6 & 7 & 8 & 9 & 10 & Extreme \\
\hline
\end{tabular}

as well as in the Pancreatic Cancer Disease Impact Score (PACADI), ${ }^{10-121617}$ with some modification given the differences between these diseases and SSc. Validation of the EULAR ScleroID follows the internationally recommended methodology of the OMERACT filter ${ }^{15}$ (online supplemental file). This is a longitudinal, multicentric project, involving 11 European expert SSc centres and patient research partners. The project workflow and process are presented in figure 1 .

\section{Patient and public involvement}

Patient research partners were involved in all the stages of the ScleroID project, starting with project design (KF and ATK), to the identification of the relevant health dimensions, and development and validation of the ScleroID including item reduction by weighting. These steps are detailed in the sections below. Furthermore, the dissemination of the study has been supported by the patient organisation Federation of European Scleroderma Associations (FESCA) by invited presentations of the preliminary results at patient congresses.

\section{Part 1: development of the SclerolD questionnaire} Identification, prioritisation and selection of the health dimensions for the SclerolD

Initially, 24 patients with SSc participated in a nominal group technique exercise and selected candidate health dimensions with the highest impact on their disease status. First, the expert investigators ( $\mathrm{RD}, \mathrm{MB}$ and $\mathrm{TH}$ ) presented a review of the literature on PROMs used in SSc. The patient representatives thereafter suggested health dimensions on which the disease has an important impact, according to their personal perception. On day one, 66 health dimensions were collected. On the second day, these were discussed and grouped by the patients according to the main concept that they are referring to, under moderation by TH. Finally, 17 candidate dimensions were unanimously selected (further details in online supplemental annex 2).

Subsequently, the identified health dimensions were evaluated by a larger group of SSc patients from all 11 participating centres. The objective of this exercise was to optimise face validity and to prioritise the dimensions. The health dimensions were translated by the investigators and patient research partners into each language (online supplemental file). Patients were presented with the list of candidate health dimensions in a random order and asked to rank them according to a decreasing order of importance. The top 10 dimensions based on median ranking were selected by the steering committee $(\mathrm{MB}, \mathrm{RD}, \mathrm{KF}$, ATK, TH and OD) for the final ScleroID. The limitation to 10 dimensions was chosen based on ranking and aiming for a better feasibility of the final questionnaire and focussing on the most relevant health dimensions reported by the SSc patient research partners. 
Development of the SclerolD questionnaire

The experts (MB, RD, TH and OD) developed one question with Numeric Rating Scales (NRS) to assess each of the selected top 10 health dimensions. The ScleroID questionnaire was subsequently translated into all applicable languages following the protocol detailed in online supplemental file.

\section{Part 2: weighting of the dimensions and validation of SclerolD}

Study design

A cross-sectional international observational cohort study with longitudinal reliability and sensitivity to change arms was performed. Patients above 18 years of age fulfilling the American College of Rheumatology/European Alliance of Associations for Rheumatology (ACR/EULAR) 2013 classification criteria for SSc were prospectively included. ${ }^{18}$ Patients with severe comorbidities not related to SSc were excluded (eg, concomitant inflammatory disease, organ failure, recent acute cerebrovascular event, serious psychiatric or neurological disease). All patients signed written informed consent.

The sample target for the cohort study was 500 patients for the cross-sectional arm and 100/150 patients for reliability/ sensitivity to change longitudinal arms, respectively, based on previous experiences with RAID and PsAID. As comparator questionnaires for the ScleroID, the most frequently used global PROMs applied in SSc were selected (online supplemental file).

\section{Data collection}

Clinical and demographic data were collected according to the European Scleroderma Trials and Research group (EUSTAR) standards $^{19}$ (online supplemental file). In addition, patients completed the ScleroID questionnaire, the selected comparators (SSc-HAQ, EQ-5D, SF-36), patient's global assessment on a Visual Analogue Scale (VAS), specific questions on the state of disease and a minimal clinically important difference question (online supplemental table S1) at all visits (online supplemental file). ${ }^{20-25}$ For the weighting procedure, in order to assess the relative impact of the health dimensions, patients were asked to distribute 100 points between the 10 dimensions of the ScleroID according to the perceived impact on their health (online supplemental file). This was the basis for calculation of the ScleroID score (see statistical methods). Patients considered to be in a stable state by the physician and with no foreseeable change in treatment or medical intervention in the next 10 days following the baseline visit were included into the reliability arm, and asked to complete the reliability questionnaire at $7 \pm 3$ days after the baseline visit (online supplemental annex). Patients considered to have active disease by the treating physician were included into the sensitivity to change arm and completed the respective questionnaire at the 12 months visit and/or at the 6 months visit, if available (online supplemental annex).

\section{Statistical analysis}

The calculation of the ScleroID score was based on the ranking of the weights, as performed in RAID, PsAID and PACADI. ${ }^{10-12} 1617$ Mean and median weights were calculated for each health dimension, after which mean and median ranks were computed for the whole cohort. These represent the basis for calculating the final weight, which is multiplied by the value on the NRS for each dimension/item and summed up for the final ScleroID score, which is then divided by 100 .

The validation of ScleroID psychometric properties was performed according to the OMERACT filter, which assesses three main features: feasibility, truth and discrimination. ${ }^{15}$ Feasibility addresses the applicability of the ScleroID questionnaire. Truth encompasses face validity (does the measure make sense), and content validity (eg, distribution of the score, floor/ceiling effect). As other measures of truth, internal consistency using Cronbach's alpha and construct validity (concurrent validity) with Pearson correlations to other scores (SSc-HAQ, SF-36, EQ-5D) were calculated. Construct validity was also investigated using a confirmatory factor analysis (online supplemental file). In addition, we assessed reliability and sensitivity to change. In the reliability arm, patients, who reported themselves as 'stable', were included in the test-retest reliability (reproducibility) analysis by assessing the intraclass correlation coefficient and agreement by Bland-Altman plot. In the sensitivity to change arm, patients reporting themselves as 'not stable' were included in the sensitivity to change (responsiveness) analysis by the standardised response mean (SRM, which is the difference in the baseline and follow-up mean values divided by the SD of the change scores). CIs were obtained by bootstrapping.

\section{RESULTS}

\section{Part 1: development of the SclerolD questionnaire}

Identification and prioritisation of health dimensions for the SclerolD In the initial nominal group exercise, 24 patient research partners selected 17 health dimensions reflecting the impact of SSc (table 1). An additional cohort of 108 patients (online supplemental table S2) subsequently prioritised these health dimensions. The selected health dimensions and their prioritisation are summarised in table 1 .

\section{Selection of health dimensions and development of the SclerolD questionnaire}

The steering committee agreed unanimously to include the ten health dimensions rated with the highest priority into the ScleroID questionnaire. One question with appropriate anchors to assess each of the selected ten health dimensions was developed by the steering committee (MB, RD, KF, ATK, TH and OD). These questions formed the ScleroID questionnaire (table 2), which was also agreed on by the patient research partners.

\section{Part 2: weighting and validation of the SclerolD questionnaire Cohort study}

In total, 472 SSc patients from nine countries (France, Italy, Hungary, Poland, Romania, Spain, Sweden, Switzerland, UK) were included in the cross-sectional cohort study.

Most patients were female $(84.8 \%)$, more than one-third had diffuse cutaneous SSc (dcSSc, 37.5\%) and the median age was 57 years. The various disease manifestations, including lung fibrosis (42.6\%), pulmonary arterial hypertension (7\%), gastrointestinal (GI) involvement ( $>60 \%$ of patients with oesophageal symptoms), articular involvement $(4.4 \%$ with synovitis) and digital ulcers $(24.0 \%$ with previous ulcers, $13.0 \%$ with current ulcers) were well represented, reflecting a typical SSc population (table 3).

\section{Weighting of the health dimensions and calculation of the SclerolD} score

Overall, valid data on weighting was provided by 446 (94\%) patients, and 462 (98\%) patients provided complete data on the ScleroID questionnaire.

The health dimensions which were assigned the highest weights (and thus highest impact) by the patients were Raynaud's phenomenon, fatigue, hand function and pain, followed by 
Table 3 Characteristics of the patients with SSc included in the weighting and validation cohort study

\begin{tabular}{|c|c|c|}
\hline Characteristics & Overall & $\%$ of missingness \\
\hline Age, years, median (IQR) & $57(48-65)$ & 1.1 \\
\hline Female gender $(\mathrm{n}, \%)$ & $396(84.8)$ & 1.1 \\
\hline Time since RP onset, years, median (IQR) & $11(5.8-20)$ & 26.3 \\
\hline $\begin{array}{l}\text { Time since first non-RP manifestations, years, median } \\
\text { (IQR) }\end{array}$ & $9(4.7-15)$ & 5.5 \\
\hline Diffuse cutaneous SSC (n, \%) & $152(37.5)$ & 14.2 \\
\hline Limited cutaneous SSC (n, \%) & $253(62.5)$ & 14.2 \\
\hline mRSS, median (IQR) & $4(0-8)$ & 26.5 \\
\hline Presence of Raynaud's phenomenon $(n, \%)$ & $332(94.6)$ & 25.6 \\
\hline Digital ulcers $(n, \%)$ & $47(13)$ & 23.5 \\
\hline Joint contractures $(n, \%)$ & $124(35.7)$ & 26.5 \\
\hline Joint synovitis (n, \%) & $15(4.4)$ & 28.4 \\
\hline Oesophageal symptoms (dysphagia, reflux) (n, \%) & $232(60.3)$ & 18.4 \\
\hline Stomach symptoms (early satiety, vomiting) ( $n, \%)$ & $61(17.6)$ & 26.5 \\
\hline $\begin{array}{l}\text { Intestinal symptoms (diarrhoea, bloating, constipation) } \\
(n, \%)\end{array}$ & $135(33.8)$ & 15.5 \\
\hline Malabsorption syndrome $(n, \%)$ & $18(7.4)$ & 48.7 \\
\hline Dyspnoea, NYHA stages III and IV (n, \%) & $27(9.6)$ & 40.7 \\
\hline FVC, \% predicted, median (IQR) & $95(82-108)$ & 40.5 \\
\hline FVC $<80 \%$ predicted $(n, \%)$ & $58(20.6)$ & 40.5 \\
\hline $\mathrm{DLCO} / \mathrm{SB}, \%$ predicted, median (IQR) & $69(55-81)$ & 44.9 \\
\hline DLCO/SB, $<70 \%$ predicted $(\mathrm{n}, \%)$ & $133(51.2)$ & 44.9 \\
\hline Lung fibrosis detected by HRCT $(n, \%)$ & $78(42.6)$ & 61.2 \\
\hline Pulmonary hypertension $(n, \%)$ & $19(6.6)$ & 39.4 \\
\hline PAPsys, mm Hg, median (IQR) & $28(24-32)$ & 54.4 \\
\hline LVEF, \%, median (IQR) & $60(55-65)$ & 35.4 \\
\hline ANA positive $(n, \%)$ & $319(96.7)$ & 30.1 \\
\hline ACA positive $(n, \%)$ & $118(36.5)$ & 31.6 \\
\hline Anti-Scl-70 AB positive $(n, \%)$ & $112(35.2)$ & 32.6 \\
\hline Anti-RNA Polymerase III AB positive (n, \%) & $21(7.6)$ & 41.1 \\
\hline ESR, mm/h, median (IQR) & $17(10-30)$ & 25.2 \\
\hline CRP, mg/L, median (IQR) & $2(0.9-5)$ & 35 \\
\hline Immunosuppression (n, \%) & $59(21.2)$ & 41.1 \\
\hline
\end{tabular}

Definitions of organ manifestations according to EUSTAR. ${ }^{19}$

ACA, anticentromere antibodies; ANA, antinuclear antibodies; CRP, C reactive protein; DLCO/SB, diffusing capacity of the lung for carbon monoxide/single breath; ESR, erythrocyte sedimentation rate; EUSTAR, European Scleroderma Trials And Research; FVC, forced vital capacity; HRCT, high resolution CT; LVEF, left ventricular ejection fraction; mRSS, modified Rodnan Skin Score; NYHA, New York Heart Association; RP, Raynaud's phenomenon; Scl70, anti-Scl70 antibodies, anti-topoisomerase I antibodies; SSc, systemic sclerosis.

upper and lower GI symptoms (table 4), confirming the results from the prioritisation.

The mean ranks given in table 4 were rescaled to sum up to 1 for the final weights. The ScleroID was calculated as a composite score of the selected 10 dimensions. For each dimension, the
NRS score was multiplied by the specific weight for this item and the weighted scores were summed up (see example in table 5).

\section{Performance of ScleroID by the OMERACT filter Feasibility}

The ScleroID showed feasibility in the application, given the low proportion of missing data: ten patients $(2.1 \%)$ had missing items, compared with 36 and 37 patients with missing data for SF-36 physical/mental component summary (PCS), 8 for EQ-5D, 12 for HAQ-DI and 16 for SSc-HAQ (online supplemental table S3). The majority of participants (462 or 98\%) had complete data on the ScleroID questionnaire. Missing data were evenly distributed among the ScleroID items (no item had significantly higher missing values).

In daily practice, single items of questionnaires are frequently missing. We therefore assessed how imputation of single items affects the overall ScleroID score. When one missing item of the ScleroID score was imputed by the mean of the remaining cohort for this item, the error was minimal (up to $0.29 / 10$ or $<10 \%$, (online supplemental table S4)).

\section{Truth}

Face validity was ensured by the involvement of patient research partners in all steps of the ScleroID development. ${ }^{26}$

The ScleroID score range is $0-10$, the actual median and IQR in our patients was $3.2(1.9-4.7)$ at baseline. The median and IQ for lcSSc patients was $3.3(2.0-4.7)$ and for difusse cutaneous SSc (dcSSc) patients 3.3 (1.7-4.8; online supplemental figure S2). In total, eight patients recorded a ScleroID score of 0 , while the highest observed value was 9.4. There was no relevant floor or ceiling effect, which would be assumed if $>15 \%$ of patients scored either the minimum or maximum value $\left({ }^{27}\right.$ online supplemental figure S2). The ScleroID questionnaire showed a good construct validity when correlated with the comparators $(\mathrm{SSc}-$ HAQ $r=0.73$; EQ-5D $r=-0.48$; Patient's global assessment, VAS $r=0.77$; HAQ-DI $r=0.62$; SF-36 PCS $r=-0.62$; each $\mathrm{p}<0.001$, table 6).

The internal consistency as another measure of construct validity was also strong: Cronbach's alpha for the ScleroID was 0.87 , similar to the SSc-HAQ $(0.88)$ and higher than for the EQ-5D (0.77, online supplemental table S2). We also performed a confirmatory factor analysis which suggested a bifactor model (one general factor with additional two or three factors) with good model fit indices (online supplemental table S6 and figure S2). The omega indices, which are thought to

\begin{tabular}{|c|c|c|c|c|c|c|}
\hline Dimension & Weight mean (SD) & Rank mean (SD) & Top ranked & Upper $25 \%$ & Bottom 25\% & Lowest ranked \\
\hline Raynaud & $20.9(18.9)$ & $7.8(2.6)$ & 39.0 & 65.9 & 28.0 & 16.7 \\
\hline Fatigue & $12.9(10.6)$ & $7.6(2.0)$ & 23.7 & 58.5 & 25.6 & 18.2 \\
\hline Hand function & $12.1(10.4)$ & $7.3(2.3)$ & 19.5 & 55.9 & 36.2 & 21.2 \\
\hline Pain & $10.4(8.7)$ & $7.0(2.3)$ & 16.7 & 46.0 & 42.2 & 23.5 \\
\hline Upper.GI symptoms & $8.0(8.2)$ & $6.4(2.4)$ & 12.3 & 37.3 & 50.6 & 36.0 \\
\hline Life choices & $7.9(8.2)$ & $6.6(2.3)$ & 12.1 & 35.8 & 52.1 & 37.9 \\
\hline Lower Gl symptoms & $7.6(9.1)$ & $6.2(2.5)$ & 11.4 & 36 & 56.1 & 42.8 \\
\hline Body mobility & $7.0(6.7)$ & $6.4(2.3)$ & 8.1 & 38.6 & 54.0 & 39.2 \\
\hline Dyspnoea & $6.8(8.8)$ & $6.1(2.4)$ & 9.3 & 33.7 & 64.4 & 46.2 \\
\hline Digital ulcers & $5.9(9.8)$ & $5.6(3.0)$ & 17.2 & 32.2 & 68.6 & 61.4 \\
\hline
\end{tabular}


Table 5 Computation of the SclerolD score

\begin{tabular}{|c|c|c|c|c|c|c|c|c|c|c|}
\hline Element & Raynaud & Fatigue & Hand function & Pain & Life choices & $\begin{array}{l}\text { Upper GI } \\
\text { symptoms }\end{array}$ & $\begin{array}{l}\text { Body } \\
\text { mobility }\end{array}$ & $\begin{array}{l}\text { Lower GI } \\
\text { symptoms }\end{array}$ & Dyspnoea & Digital ulcers \\
\hline SclerolD weights & 0.117 & 0.114 & 0.109 & 0.104 & 0.098 & 0.096 & 0.095 & 0.093 & 0.091 & 0.083 \\
\hline $\begin{array}{l}\text { Example NRS } \\
\text { scores }\end{array}$ & 9 & 3 & 4 & 0 & 7 & 2 & 6 & 4 & 0 & 3 \\
\hline weights $(\mathrm{x})$ scores & $0.117 \times 9$ & $0.114 \times 3$ & $0.109 \times 4$ & $0.104 \times 0$ & $0.098 \times 7$ & $0.096 \times 2$ & $0.095 \times 6$ & $0.093 \times 4$ & $0.091 \times 0$ & $0.083 \times 3$ \\
\hline$=$ & 1.053 & 0.342 & 0.436 & 0 & 0.686 & 0.192 & 0.57 & 0.372 & 0 & 0.249 \\
\hline SclerolD = & 3.9 & & & & & & & & & \\
\hline
\end{tabular}

Example of computation of the SclerolD score for a given patient. The final score is computed using a weighted sum over the NRS (0-10) scores given to each dimension by the patient. The weights sum to 1, and are proportional to the mean ranks given to each dimension.

GI, gastrointestinal tract; NRS, Numeric Rating Scale; ScleroID, Systemic Sclerosis Impact of Disease.

be superior to Cronbach's alpha, ${ }^{28} 29$ suggested not only good model fit for the bifactor models (online supplemental table S7), but also supported our claim for sufficient unidimensionality to justify the use of a sum score (see also online supplemental file).

\section{Test-retest reliability}

In total, 109 patients were included in the longitudinal reliability arm and completed a second visit at $7 \pm 3$ days after baseline. The ScleroID had a very good test-retest reliability, with an intraclass correlation coefficient of 0.84 (ranging $0.61-0.79$ for the individual items), superior to all comparators (online supplemental table S8); see also Bland-Altman plot for agreement in online supplemental figure S5).

\section{Sensitivity to change}

A total of 113 patients were included and had a median follow-up visit at 12.2 (IQR 11.5-13.1) months. The sensitivity to change for the ScleroID was estimated using the SRM between baseline and follow-up, using only those patients $(n=37)$ reporting disease status as not-stable (table 7). The SRM is computed for all patients regardless of whether they report improved/worsened disease state, and then separately for those with improved and worsened state (table 7). The ScleroID performed better than all other comparator PROMs in indicating overall change. This performance was even better in patients who experienced improvement (table 7).

Table 6 Construct validity analysis by correlation between SclerolD and other established PROMs

\begin{tabular}{lc}
\hline Variable & $\begin{array}{c}\text { Pearson correlation } \\
\text { coefficient* }\end{array}$ \\
\hline Physician's Global Assessment & $0.28(0.05)$ \\
\hline Patient's Global Assessment & $0.77(0.03)$ \\
SF-36 Physical Component Score & $-0.62(0.03)$ \\
SF-36 Mental Component Score & $-0.47(0.03)$ \\
HAQ-DI & $0.62(0.03)$ \\
SSC-HAQ & $0.73(0.02)$ \\
EQ-5D (UK-weighted) & $-0.48(0.04)$ \\
VAS-GIT & $0.38(0.05)$ \\
VAS-Dyspnoea & $0.38(0.04)$ \\
VAS-Raynaud & $0.42(0.04)$ \\
VAS-Ulcers & $0.37(0.05)$ \\
\hline *Bootstrap standard errors (SEs) of estimated correlation given in brackets. \\
EQ-5D, EuroQol Five Dimensional Questionnaire; GIT, gastrointestinal tract; HAQ-DI, Health \\
Assessment Questionnaire Disability Index; PROMs, patient-reported outcome measures; \\
SclerolD, Systemic Sclerosis Impact of Disease; SF-36, Short Form (36) Health Survey; SSc, \\
Systemic sclerosis; VAS, Visual Analogue Scale.
\end{tabular}

\section{DISCUSSION}

PROMs are being developed to capture the patient's aspects of a disease, that is, the specific patient experience beyond the disease manifestations that are in the physician's focus, which are typically lethal or associated with high morbidity. Especially in SSc, which has a high morbidity and mortality as well as a high work disability, there is a discordance between the patient's experience and the physician's assessment, exemplified by differences in the patient's and physician's global assessment. ${ }^{30-32}$ This was also observed in this study, underlining the need to implement PROMs in the clinical assessment and shared decision making. Most PROMs used in SSc are legacy questionnaires adapted from other diseases and not SSc-specific instruments.

Hence, specific PROMs are needed, although some have tried to incorporate the patient's view. ${ }^{73}$

We have developed and validated the ScleroID questionnaire as a global measurement tool to assess the disease burden in SSc patients. The questionnaire is simple and easy to apply, has high internal consistency and shows good correlation with the patient global assessment and the SSc-HAQ. Although weighting reflects patient experience, it does not significantly change the overall score. It is planned to develop a calculator (or app) to provide final scores. The ScleroID health dimensions have a high face validity due to the inclusion of SSc patient research partners throughout the development and validation process. Notably, main dimensions of the ScleroID questionnaire such as dyspnoea, pain, digital ulcers, GI symptoms or fatigue were also associated with a high self-reported disability and high disease burden in other reports from the literature. ${ }^{534}$

The ScleroID questionnaire has a very good retest reliability, which is even better than comparators and has better sensitivity to change than the comparators used. This is especially important as a high percentage of patients are relatively stable, but progression of the disease drives mortality and morbidity. ${ }^{35}$ In addition, other frequently used major outcomes of SSc studies, such as the mRSS, show a relatively low sensitivity to change, which might partially explain the many randomised clinical trials with borderline significance using the mRSS as a primary outcome. ${ }^{36}$

\section{Comparison to other PROMs}

In contrast to other validated PROMs that have not been developed specifically for SSc (such as Patient-Reported Outcomes Measurement Information System-29; PROMIS-29) ${ }^{37-39}$ or have only been adapted to SSc (such as the Scleroderma Health Assessment Questionnaire (SHAQ)) $)^{39} 40$, the ScleroID questionnaire was specifically developed, with involvement of SSc patient research partners. Although other specific PROMs for SSc have been developed, the Symptom Burden Index and the Systemic Sclerosis Questionnaire (SySQ) did not involve the target 
Table 7 Sensitivity to change of the SclerolD compared with other PROMs

\begin{tabular}{|c|c|c|c|c|c|c|}
\hline Variable & SRM (all) & $95 \% \mathrm{Cl}$ (all) & SRM (improved) & $95 \% \mathrm{Cl}$ (improved) & SRM (worsened) & $95 \% \mathrm{Cl}$ (worsened) \\
\hline SclerolD & $0.57(36)$ & 0.31 to 0.86 & $0.76(20)$ & 0.42 to 1.23 & $-2.31(4)$ & -25.14 to -1.35 \\
\hline Raynaud & $0.08(37)$ & -0.26 to 0.4 & $0.21(20)$ & -0.25 to 0.68 & $-1.50(4)$ & - to -1.17 \\
\hline Hand function & $-0.20(36)$ & -0.57 to 0.11 & $-0.22(20)$ & -0.77 to 0.22 & $-0.78(4)$ & -3.5 to -0.5 \\
\hline Pain & $0.01(37)$ & -0.23 to 0.45 & $0.04(20)$ & -0.39 to 0.51 & $0.00(4)$ & -1.5 to 1.5 \\
\hline Fatigue & $0.24(37)$ & -0.08 to 0.54 & $0.40(20)$ & 0 to 0.79 & $-1.306(4)$ & - to -0.5 \\
\hline Upper Gl symptoms & $0.56(37)$ & 0.33 to 0.81 & $0.58(20)$ & 0.25 to 0.99 & $-(4)$ & - \\
\hline Lower GI symptoms & $0.44(37)$ & 0.09 to 0.82 & $0.43(20)$ & -0.03 to 1.07 & $-(4)$ & - \\
\hline Life Choices & $0.53(37)$ & 0.25 to 0.87 & $0.77(20)$ & 0.33 to 1.51 & $0.50(4)$ & 0.5 to 1.5 \\
\hline Body mobility & $0.35(37)$ & 0.03 to 0.63 & $0.54(20)$ & 0.14 to 1 & $0.00(4)$ & -1.5 to 1.5 \\
\hline Dyspnoea & $0.50(37)$ & 0.2 to 0.85 & $0.65(20)$ & 0.25 to 1.24 & $0.00(4)$ & -1.5 to 1.5 \\
\hline Digital ulcers & $-0.09(36)$ & -0.43 to 0.23 & $0.00(20)$ & -0.62 to 0.39 & $-0.5(4)$ & -1.5 to -0.5 \\
\hline Patient's Global Assessment & $0.29(36)$ & -0.04 to 0.66 & $0.57(20)$ & 0.22 to 1.02 & $-0.20(4)$ & -1.5 to 1.5 \\
\hline Physician's Global Assessment & $0.09(29)$ & -0.26 to 0.47 & $0.31(17)$ & -0.18 to 0.9 & $-0.5(4)$ & -1.5 to -0.5 \\
\hline SF-36 Physical Component Score & $-0.2(37)$ & -0.53 to 0.08 & $-0.45(20)$ & -0.85 to -0.07 & $10.96(4)$ & 9.25 to 128.35 \\
\hline SF-36 Mental Component Score & $-0.08(37)$ & -0.4 to 0.26 & $-0.18(20)$ & -0.64 to 0.31 & $-0.24(4)$ & -1.22 to 2.65 \\
\hline HAQ-DI & $-0.01(36)$ & -0.39 to 0.32 & $0.10(19)$ & -0.34 to 0.61 & $-0.78(4)$ & -2.6 to -0.5 \\
\hline SSC HAQ & $0.15(34)$ & -0.23 to 0.45 & $0.24(18)$ & -0.26 to 0.69 & $-0.46(4)$ & -5.5 to 0.5 \\
\hline$E Q-5 D$ & $0.41(37)$ & 0.09 to 0.74 & $0.33(20)$ & -0.09 to 0.74 & $1.42(4)$ & 1.25 to 9.94 \\
\hline
\end{tabular}

EQ-5D, EuroQol Five Dimensional; Gl, gastrointestinal; HAQ-DI, Health Assessment Questionnaire Disability Index; PROMs, patient-reported outcome measures; SclerolD, Systemic Sclerosis Impact of Disease; SF-36, Short Form (36) Health Survey; SRM, standardised response mean; SSc, systemic sclerosis.

population for dimension/item generation. The Scleroderma Assessment Questionnaire (SAQ), which is based on the SysQ, had only partial involvement of patients. ${ }^{41}{ }^{42}$ However, these questionnaires have only been partially validated, mostly lacking a discriminant validity analysis, and are partly not validated in English (SysQ and SAQ). The recently published PROM Cochin Scleroderma Functional scale 17, a 17-item PROM that focused on mobility and general task aspects of SSc, was also developed with involvement of SSc patients. ${ }^{43}$ It has been evaluated in a smaller cohort than the ScleroID and in French only, with data on discriminant validity (sensitivity to change) still missing.

\section{Limitations of the study}

Although patients with diverse disease manifestations participated in the nominal group exercise, disease-related or demographic data were not prospectively collected at this early stage. Patients included in the cross-sectional analysis had to fulfil the ACR/EULAR 2013 classification criteria for SSc but there were no recommendations concerning disease subtype or organ involvement. The final selection of participants by the centres has an impact on the weighting of the ScleroID dimensions and the cross-sectional part included mainly patients with longstanding disease. However, our cohort reflects other observational cohorts such as the EUSTAR registry, etc, indicating that it is a representative SSc population. Although SSc patients often acquire expert knowledge about their disease and are aware that the questionnaire evaluates SSc-related burden, it might be difficult at times to distinguish symptoms related to SSc from common, unrelated symptoms, for example, as in the case of GI problems. This is however common to all PROMs.

Another potential limitation is the relative paucity of patients who experience change of their disease status, who then enter the sensitivity to change analysis. As this change was anchored by the patients themselves, there were no prior data to guide selection of these patients.

The ScleroID was designed as an overall measure of disease impact. It was derived from patients under routine clinical care and as such, it is still to be validated in clinical trials aiming at overall disease modification. If the ScleroID questionnaire can also be used for clinical trials focusing on organ-specific disease progression is subject to further analysis.

In summary, the ScleroID questionnaire is a unique, easy to apply, SSc-specific PROM that has been successfully validated in a large European clinical cohort using multiple translations. It should be further validated for clinical trials and in large registries and has the potential to measure disease impact that will be more meaningful for patients and health authorities than currently used approaches.

\section{Author affiliations}

${ }^{1}$ Department of Rheumatology, University Hospital of Zurich, Zurich, Switzerland ${ }^{2}$ Department of Psychology, Psychological Methods, Evaluation and Statistics, University of Zurich, Zurich, Switzerland

${ }^{3}$ Department of Psychology, Psychological Methodology, University of Leipzig, Leipzig, Germany

${ }^{4}$ Scleroderma and Raynaud's UK, London, UK

${ }^{5}$ Federation of the European Scleroderma Associations (FESCA) aisbl, Tournai, Belgium

${ }^{6}$ Federation of European Scleroderma Associations (FESCA), Saint Maur, Belgium ${ }^{7}$ Department of Rheumatology A, Descartes University, APHP, Cochin Hospital, Paris, France

${ }^{8}$ Department of Rheumatology, Hospital Universitario 12 de Octubre, Madrid, Spain ${ }^{9}$ Department of Rheumatology and Immunology, University of Pécs, Pécs, Hungary

${ }^{10}$ Centre for Rheumatology, University College London, Royal Free Campus, London, UK

${ }^{11}$ Department of Rheumatology, Lund University, Lund, Sweden

${ }^{12}$ Department of Rheumatology and Internal Medicine, Medical University of Bialystok, Bialystok, Poland

${ }^{13}$ Department of Experimental and Clinical Medicine, Division of Rheumatology AOUC, University of Florence, Florence, Italy

${ }^{14}$ IRCCS San Raffaele Hospital, Unit of Immunology, Rheumatology, Allergy and Rare diseases (UnIRAR), Milan, Italy

${ }^{15}$ Department of Internal Medicine and Rheumatology, Cantacuzino Hospital, Carol Davila University of Medicine and Pharmacy, Bucharest, Romania

${ }^{16}$ Department of Rheumatology and Clinical Immunology, Justus-Liebig University

Giessen, Campus Kerckhoff, Bad Nauheim, Germany

${ }^{17}$ Division of Rheumatology and Research, Diakonhjemmet Hospital, Oslo, Norway

${ }^{18}$ Regional Research Support, Oslo University Hospital, Oslo, Norway

\section{Presented at}

Part of this work has previously been presented, as follows: Presentations: The EULAR Systemic Sclerosis Impact of Disease score - a new patient-reported outcome measure under development, 4th Scleroderma World Congress, Patient Congress, Lisbon, Feb 18th - 20th, 2016, Poster EULAR 2016, Poster ACR 2016, Abstract book EULAR 2017, Poster ACR 2017, Poster Patients' Congress SWC 02/2018 Bordeaux, 
Abstract book EULAR 2018. Meetings: Working group patients and Pls inkl. teleconference - Rome, 06/2015, Task force meetings, EULAR 06/2016 London, ACR 11/2016 Washington, EULAR 06/2017 Madrid, EULAR 2020 Online E-Congress.

Acknowledgements We sincerely thank the patients' representatives who contributed to the study, without whom this project would not have been possible: Ann Kennedy, Kim Fligelstone, Heleen Lever, Yanne Perriault, Anna Vegh, Susanne Tuppeck, Silvia-Daniela Sandulescu, Mervat Gaafar, Barbara Zappitello, Rachida Amrouch, Grazia Tassini, Helene Kambourakis, Elisabeth Scheel, Stephan Houbertz, Beata Garay Toth, Ana Marcela Badea, Stefana Dumitru, Alicia García Oliva, Begoña María Gorricho Corta, Johanna Berglind, Natalie Perruchoud, Alice Martins Correia, Richard Dodds, Nicola Whitehill. Our thoughts go to Mr. Richard Dodds, who unfortunately is no longer with us.

Contributors The authors as listed on the title page of the manuscript have all made substantial contributions which qualifies them as authors. All authors contributed to critical revisions and approved the final version of the manuscript. MB: design of the study, acquisition of data, analysis, interpretation of data, drafting and revising the article. RDo: design of the study, acquisition of data, analysis, interpretation of data, drafting and revising the article. AG: analysis, interpretation of data, drafting and revising the article. RDe: interpretation of data, revising the article. KF: design of the study, acquisition of data, interpretation of data, revising the article. ATK: design of the study, acquisition of data, interpretation of data, revising the article. AR: acquisition of data, interpretation of data, revising the article. YA: acquisition of data, analysis, interpretation of data, revising the article. PEC: acquisition of data, analysis, interpretation of data, revising the article. LC: acquisition of data, analysis, interpretation of data, revising the article. CPD: acquisition of data, analysis, interpretation of data, revising the article. RH: acquisition of data, analysis, interpretation of data, revising the article. GS: acquisition of data, analysis, interpretation of data, revising the article. OK-B: acquisition of data, analysis, interpretation of data, revising the article. CB: acquisition of data, analysis, interpretation of data, revising the article. MM-C: acquisition of data, analysis, interpretation of data, revising the article. CM: acquisition of data, analysis, interpretation of data, revising the article. AMG: acquisition of data, analysis, interpretation of data, revising the article. UM-L: acquisition of data, interpretation of data, revising the article. IS: design of the study, analysis, interpretation of data, revising the article. TKK: design of the study, analysis, interpretation of data, revising the article. TH: design of the study, acquisition of data, analysis, interpretation of data, drafting and revising the article. OD: design of the study, acquisition of data, analysis, interpretation of data, drafting and revising the article, guarantor.

Funding The development and validation of the SclerolD was in part supported by a grant from EULAR.

Competing interests MB personal fees from Amgen and Bayer, outside the submitted work. RDo reports grants from Articulum Fellowship, sponsored by Pfizer (2013-2014), grants from Actelion, personal fees from Actelion and BoehringerIngelheim, outside the submitted work. AG none with respect to the study. RDe none with respect to the study.KF none with respect to the study. ATK none with respect to the study. AR none with respect to the study. YA reports grants and personal fees from Bayer, Boehringer-Ingelheim, Bristol Myers Squibb, Curzion, Inventiva, Roche and Sanofi during the conduct of the study. PEC reports consultancy relationship and/or research grants from: Abbvie, Actelion, Bayer, Boehringer Ingelheim, Corbus Pharma, Emerald Health Pharmaceuticals, Galapagos, Gesynta Pharma, Inventiva, iQvia, Mitsubishi Tanabe Pharma, MSD, Roche and Sanofi Genzyme. LC none with respect to the study. CPD reports grants and personal fees from GSK, Mitsubishi Tanabe Pharma, Boehringer-Ingelheim, Servier, Arxx Therapeutics, Bayer, Inventiva, Galapagos, Horizon, Roche, CSL Behring, Sanofi during the conduct of the study.RH reports personal lecture fees from Actelion Pharmaceuticals Sweden AB, BoehringerIngelheim Sweden $A B$, and Roche Sweden $A B$, and has been co-investigator in clinical trials for United Therapeutics and Actelion Pharmaceuticals Sweden $A B$, and has been involved in research advisory boards for Actelion Pharmaceuticals Sweden $A B$ and Boehringer-Ingelheim Sweden AB. GS none with respect to the study. OK-B reports personal fees and/or congress support from Bayer, Boehringer Ingelheim, CSL Behring, Gilead, Inventiva, Medac, MSD, Novartis, Pfizer, Roche, Sandoz, outside the submitted work. CB reports personal fees from Actelion, personal fees from Boehringer-Ingelheim, personal fees from Eli Lilly, grants from Gruppo Italiano Lotta alla Sclerodermia (GILS), grants from New Horizon Fellowship, grants from European Scleroderma Trials and Research (EUSTAR), grants from Foundation for Research in Rheumatology (FOREUM), grants from Fondazione Italiana per la Ricerca sull'Artrite (FIRA), outside the submitted work. MM-C reports grants and personal fees from Actelion, personal fees from Biogen, personal fees from Bayer, personal fees from Boehringer Ingelheim, personal fees from CSL Behring, personal fees from Eli-Lilly, outside the submitted work. CM reports personal fees from Boehringer Ingelheim, Eli-Lilly, Mepha, MEDTalks Switzerland and congress support from Actelion and Roche, outside the submitted work. AMG reports consultancy fees from BoehringerIngelheim and congress support from Abbvie and Novartis, outside the submitted work. UM-L none with respect to the study. JS none with respect to the study. TKK none with respect to the study. TH reports no conflicts of interest.OD has/ had consultancy relationship and/or has received research funding in the area of potential treatments of scleroderma and its complications from (last three years): Abbvie, Acceleron Pharma, Alexion, Amgen, AnaMar, Arxx Therapeutics, Baecon Discovery, Bayer, Boehringer Ingelheim, Catenion, Drug Development International, CSL Behring, ChemomAb, GSK, Horizon (Curzion) Pharmaceuticals, Inventiva, Italfarmaco, iQvia, Lilly, Medac, Medscape, Mitsubishi Tanabe Pharma, MSD, Novartis, Pfizer, Roche, Sanofi, Serodapharm, Target Bio Science and UCB In addition, he has a patent mir-29 for the treatment of systemic sclerosis issued (US8247389, EP2331143).

Patient consent for publication Not applicable.

Ethics approval The project was approved by the ethics committee in each participating centre.

Provenance and peer review Not commissioned; externally peer reviewed.

Data availability statement Data are available on reasonable request. On request, and subject to review by the steering committee, access can be granted to the anonymised raw data and the $R$ code. Deidentified data will be made available via secure data transfer. Data requests may be sent to the SclerolD steering committee, represented by OD, Department of Rheumatology, University Hospital Zurich, University of Zurich, Switzerland. Email oliver.distler@usz.ch.

Supplemental material This content has been supplied by the author(s). It has not been vetted by BMJ Publishing Group Limited (BMJ) and may not have been peer-reviewed. Any opinions or recommendations discussed are solely those of the author(s) and are not endorsed by BMJ. BMJ disclaims all liability and responsibility arising from any reliance placed on the content. Where the content includes any translated material, BMJ does not warrant the accuracy and reliability of the translations (including but not limited to local regulations, clinical guidelines, terminology, drug names and drug dosages), and is not responsible for any error and/or omissions arising from translation and adaptation or otherwise.

\section{ORCID iDs}

Mike O Becker http://orcid.org/0000-0001-9102-3088

Rucsandra Dobrota http://orcid.org/0000-0001-9819-7574

Rudolf Debelak http://orcid.org/0000-0001-8900-2106

Christopher P Denton http://orcid.org/0000-0003-3975-8938

Cosimo Bruni http://orcid.org/0000-0003-2813-2083

Marco Matucci-Cerinic http://orcid.org/0000-0002-9324-3161

Carina Mihai http://orcid.org/0000-0002-8627-8817

Oliver Distler http://orcid.org/0000-0002-0546-8310

\section{REFERENCES}

1 Allanore Y, Simms R, Distler O, et al. Systemic sclerosis. Nat Rev Dis Primers 2015;1:15002.

2 Varga J. Systemic sclerosis: an update. Bull NYU Hosp Jt Dis 2008:66:198-202.

3 Elhai M, Meune C, Boubaya M, et al. Mapping and predicting mortality from systemic sclerosis. Ann Rheum Dis 2017;76:1897-905.

4 Proudman SM, Huq M, Stevens W, et al. What have multicentre registries across the world taught us about the disease features of systemic sclerosis? J Scleroderma Relat Disord 2017:2:169-82.

5 Jaeger VK, Distler O, Maurer B, et al. Functional disability and its predictors in systemic sclerosis: a study from the DeSScipher project within the EUSTAR group. Rheumatology 2018;57:441-50.

6 Frantz C, Avouac J, Distler O, et al. Impaired quality of life in systemic sclerosis and patient perception of the disease: a large international survey. Semin Arthritis Rheum 2016:46:115-23.

7 Pauling JD, Caetano J, Campochiaro C, et al. Patient-Reported outcome instruments in clinical trials of systemic sclerosis. Journal of Scleroderma and Related Disorders 2020;5:90-102.

8 Revicki DA, Gnanasakthy A, Weinfurt K. Documenting the rationale and psychometric characteristics of patient reported outcomes for labeling and promotional claims: the pro evidence dossier. Qual Life Res 2007;16:717-23.

9 Nelson EC, Eftimovska E, Lind C, et al. Patient reported outcome measures in practice. BMJ 2015;350:g7818.

10 Gossec L, Dougados M, Rincheval N, et al. Elaboration of the preliminary rheumatoid arthritis impact of disease (raid) score: a EULAR initiative. Ann Rheum Dis 2009:68:1680-5.

11 Gossec L, Paternotte S, Aanerud GJ, et al. Finalisation and validation of the rheumatoid arthritis impact of disease score, a patient-derived composite measure of impact of rheumatoid arthritis: a EULAR initiative. Ann Rheum Dis 2011;70:935-42.

12 Gossec L, de Wit M, Kiltz U, et al. A patient-derived and patient-reported outcome measure for assessing psoriatic arthritis: elaboration and preliminary validation of the psoriatic arthritis impact of disease (PSAID) questionnaire, a 13-country EULAR initiative. Ann Rheum Dis 2014:73:1012-9.

13 Dougados M, Brault Y, Logeart I, et al. Defining cut-off values for disease activity states and improvement scores for patient-reported outcomes: the example of the rheumatoid arthritis impact of disease (raid). Arthritis Res Ther 2012;14:R129. 
14 Dougados M, Ripert M, Hilliquin P, et al. Onset of action of etanercept in rheumatoid arthritis based on patient-reported outcomes. Clin Exp Rheumatol 2012;30:266-8.

15 Tugwell P, Boers M, D'Agostino M-A, et al. Updating the OMERACT filter: implications of filter 2.0 to select outcome instruments through assessment of "truth": content, face, and construct validity. J Rheumatol 2014;41:1000-4.

16 Heiberg T, Baekelandt B, Kvien TK, et al. Psychometric performance of the pancreatic cancer disease impact (PACADI) score. Pancreatology 2019;19:971-8.

17 Heiberg T, Nordby T, Kvien TK, et al. Development and preliminary validation of the pancreatic cancer disease impact score. Support Care Cancer 2013;21:1677-84.

18 van den Hoogen F, Khanna D, Fransen J, et al. 2013 classification criteria for systemic sclerosis: an American College of rheumatology/European League against rheumatism collaborative initiative. Ann Rheum Dis 2013;72:1747-55.

19 Walker UA, Tyndall A, Czirják L, et al. Clinical risk assessment of organ manifestations in systemic sclerosis: a report from the EULAR scleroderma trials and research Group database. Ann Rheum Dis 2007;66:754-63.

20 Allanore Y, Bozzi S, Terlinden A, et al. Health assessment Questionnaire-Disability index (HAQ-DI) use in modelling disease progression in diffuse cutaneous systemic sclerosis: an analysis from the EUSTAR database. Arthritis Res Ther 2020;22:257.

21 Poole JL, Williams CA, Bloch DA, et al. Concurrent validity of the health assessment questionnaire disability index in scleroderma. Arthritis Care Res 1995;8:189-93.

22 Georges C, Chassany O, Mouthon L, et al. Validation of French version of the scleroderma health assessment questionnaire (SSC HAQ). Clin Rheumatol 2005;24:3-10.

23 Gualtierotti R, Ingegnoli F, Scalone L, et al. Feasibility, acceptability and construct validity of EQ-5D in systemic sclerosis. Swiss Med Wkly 2016;146:w14394.

24 Danieli E, Airò P, Bettoni L, et al. Health-related quality of life measured by the short form 36 (SF-36) in systemic sclerosis: correlations with indexes of disease activity and severity, disability, and depressive symptoms. Clin Rheumatol 2005;24:48-54

25 Khanna D, Furst DE, Clements PJ, et al. Responsiveness of the SF-36 and the health assessment questionnaire disability index in a systemic sclerosis clinical trial. J Rheumatol 2005;32:832-40.

26 Weldring T, Smith SMS. Patient-Reported outcomes (pros) and patient-reported outcome measures (PROMs). Health Serv Insights 2013;6:61-8.

27 Terwee CB, Bot SDM, de Boer MR, et al. Quality criteria were proposed for measurement properties of health status questionnaires. J Clin Epidemiol 2007;60:34-42.

28 Dunn TJ, Baguley T, Brunsden V. From alpha to omega: a practical solution to the pervasive problem of internal consistency estimation. Br J Psychol 2014; 105:399-412.

29 Sijtsma K. On the use, the misuse, and the very limited usefulness of Cronbach's alpha. Psychometrika 2009;74:107-20.
30 Ouimet JM, Pope JE, Gutmanis I, et al. Work disability in scleroderma is greater than in rheumatoid arthritis and is predicted by high $\mathrm{HAQ}$ scores. Open Rheumatol J 2008;2:44-52.

31 Hudson M, Steele R, Lu Y, et al. Work disability in systemic sclerosis. J Rheumatol 2009;36:2481-6.

32 Hudson $\mathrm{M}$, Impens $\mathrm{A}$, Baron $\mathrm{M}$, et al. Discordance between patient and physician assessments of disease severity in systemic sclerosis. J Rheumatol 2010;37:2307-12.

33 Pauling JD, Frech TM, Domsic RT, et al. Patient participation in patient-reported outcome instrument development in systemic sclerosis. Clin Exp Rheumatol 2017;35 Suppl 106:184-92.

34 Khanna D, Allanore Y, Denton CP, et al. Patient perception of disease burden in diffuse cutaneous systemic sclerosis. J Scleroderma Relat Disord 2020;5:66-76.

35 Wu W, Jordan S, Becker MO, et al. Prediction of progression of interstitial lung disease in patients with systemic sclerosis: the SPAR model. Ann Rheum Dis 2018;77:1326-32.

36 Khanna D, Allanore Y, Denton CP, et al. Riociguat in patients with early diffuse cutaneous systemic sclerosis (RISE-SSc): randomised, double-blind, placebo-controlled multicentre trial. Ann Rheum Dis 2020;79:618-25.

37 Hinchcliff ME, Beaumont JL, Carns MA, et al. Longitudinal evaluation of PROMIS-29 and FACIT-dyspnea short forms in systemic sclerosis. J Rheumatol 2015;42:64-72.

38 Kwakkenbos L, Thombs BD, Khanna D, et al. Performance of the patientreported outcomes measurement information System-29 in scleroderma: a scleroderma patient-centered intervention network cohort study. Rheumatology 2017; 56:1302-11.

39 Pope J. Measures of systemic sclerosis (scleroderma): health assessment questionnaire (HAQ) and scleroderma HAQ (SHAQ), physician- and patient-rated global assessments, symptom burden index (Sbi), University of California, Los Angeles, scleroderma clinical trials Consortium gastrointestinal scale (UCLA SCTC GIT) 2.0, baseline dyspnea index (BDI) and transition dyspnea index (TDI) (Mahler's index), Cambridge pulmonary hypertension outcome review (camphor), and Raynaud's condition score (RCS). Arthritis Care Res 2011;63 Suppl 11:S98-111.

40 Steen VD, Medsger TA. The value of the health assessment questionnaire and special patient-generated scales to demonstrate change in systemic sclerosis patients over time. Arthritis Rheum 1997;40:1984-91.

41 Ruof J, Brühlmann P, Michel BA, et al. Development and validation of a self-administered systemic sclerosis questionnaire (SySQ). Rheumatology 1999;38:535-42.

42 Ostojić P, Damjanov N. The scleroderma assessment questionnaire (SAQ). A new selfassessment questionnaire for evaluation of disease status in patients with systemic sclerosis. Z Rheumatol 2006;65:168-75.

43 Daste C, Abdoul H, Foissac F, et al. Development of a new patient-reported outcome measure to assess activities and participation in people with systemic sclerosis: the Cochin 17-item scleroderma functional scale. Br J Dermatol 2020;183:710-8. 